\title{
A cross-cultural comparison of student learning patterns in higher education
}

\author{
Kosala N. Marambe · Jan D. Vermunt $\cdot$ Henny P. A. Boshuizen
}

Published online: 13 December 2011

(C) The Author(s) 2011. This article is published with open access at Springerlink.com

\begin{abstract}
The aim of this study was to compare student learning patterns in higher education across different cultures. A meta-analysis was performed on three large-scale studies that had used the same research instrument: the Inventory of learning Styles (ILS). The studies were conducted in the two Asian countries Sri Lanka and Indonesia and the European country The Netherlands. Students reported use of learning strategies, metacognitive strategies, conceptions of learning and learning orientations were compared in two ways: by analyses of variance of students' mean scale scores on ILS scales, as well as by comparing the factor structures of the ILS-scales between the three studies. Results showed most differences in student learning patterns between Asian and European students. However, many differences were identified between students from the two Asian countries as well. The Asian learner turned out to be a myth. Moreover, Sri Lankan students made the least use of memorising strategies of all groups. That Asian learners would have a propensity for rote learning turned out to be a myth as well. Some patterns of learning turned out to be universal and occurred in all groups, other patterns were found only among the Asian or the European students. The findings are discussed in terms of learning environment and culture as explanatory factors. Practical implications for student mobility in an international context are derived.
\end{abstract}

Keywords Learning patterns - Cross-cultural research · Learning strategies · Metacognition $\cdot$ Student learning $\cdot$ Student mobility

K. N. Marambe

Medical Education Unit, Faculty of Medicine, University of Peradeniya, Peradeniya 20400, Sri Lanka

J. D. Vermunt (两)

Faculty of Social and Behavioural Sciences, Utrecht University, Heidelberglaan 1, 3584 CS Utrecht, The Netherlands

e-mail: j.vermunt@uu.nl

H. P. A. Boshuizen

Centre for Learning Sciences and Technologies, Open University, Valkenburgerweg 177,

6419 AT Heerlen, The Netherlands 


\section{Introduction}

Student mobility in higher education is growing rapidly. Ever more students are doing part of their studies abroad, not only in neighbouring countries, but also far away at universities in other continents. Although the experience of studying abroad may be enriching in many respects, adaptation to a new study environment is not always easy. Higher education students bring with them a long history of schooling in their home country, a period in which their patterns of learning and study habits have been formed in interaction with their cultural and educational environments. These patterns of learning, including approaches to learning, regulation strategies, conceptions of learning, and learning orientations, may coincide or conflict with the way of learning that is expected in universities abroad. Wierstra et al. (2003), for example, found marked differences in educational cultures between Northern and Southern Europe as perceived by international exchange students, and associated differences in students' learning patterns. Biemans and Van Mil (2008) studied Dutch and Chinese first year students' learning patterns at a Dutch agricultural university. The study results of these Chinese students were disappointing despite hard work. The Chinese students indicated to use more reproductive, stepwise, sequential, detailed and analytic study strategies, while their Dutch colleagues reported to use more deep, structuring, and relating strategies aimed at identifying main points and constructing an overall, coherent picture of the study materials. The authors concluded that the way the Chinese students were used to learn in China, did not fit the demands of the educational system at this Dutch university, and that a lot of Chinese students experienced problems to adapt their way of learning to the Dutch educational system.

Studies such as these underline the importance of knowing more about the views, motives, study habits and cultural norms students bring with them when they go abroad for their studies. Knowing more about these differences can be highly informative about how we might support students with their adaptation to new learning environments. The past two decades have witnessed a growing interest in the study of the influence of culture on student learning. As pointed out by Hofstede (2001), learning, education and culture are strongly interrelated. Several researchers have carried out cross-cultural, qualitative studies to better understand the study habits and conceptions of learning among students from different cultural backgrounds (e.g. Charlesworth 2008; Dahlin and Watkins 2000; Kennedy 2002; Manikutty et al. 2007; Valiente 2008). In many studies attempts to memorise, yet high achievement, have been widely attributed to Asian students (Kember 1996, 2000). However, results of qualitative studies with Australian, Japanese and Chinese students indicate the need to re-examine some of the widely held beliefs about crosscultural differences in student learning (Clark and Gieve 2006; Kember 2000; Purdie et al. 1996; Purdie and Hattie 2002; Sachs and Chan 2003; Marton et al. 2005). The present study is meant to contribute to the research evidence on this issue. It is a meta-analysis, aimed to clarify some of the currently held beliefs on cross-cultural differences in student learning patterns. Learning strategies, conceptions and orientations of university students in Sri Lanka, Indonesia and The Netherlands, investigated with the same research instrument, will be compared and contrasted.

Cultural differences in student learning

Culture dependent differences in thinking and acting and their implications for education are extensively discussed in the literature. Interestingly, Hofstede (2001) identified five dimensions of culture: (1) Power distance-the extent to which the less powerful members 
of a society accept and expect that power is distributed unequally; (2) Uncertainty avoidance-the extent to which the members of a society feel comfortable or uncomfortable in unstructured situations; (3) Individualism versus collectivism - the degree to which individuals are supposed to look after themselves or remain integrated into groups; (4) Masculinity versus femininity-dominant gender role patterns in the society i.e. the degree of expression of "toughness" among males and "tenderness" among females in handling situations; and (5) Long term versus short term orientation-the extent to which a culture programs its members to accept delayed gratification of their material, social and emotional needs. He classified different countries on the different dimensions of culture and described the possible influences this could have on the educational system. Crosscultural researchers can make use of these dimensions to assess the differences and similarities of the cultures being investigated.

There is general consensus in the research literature in higher education that students exhibit a number of different approaches to learning. Qualitative and quantitative studies have confirmed a broad distinction between deep and surface approaches to learning (Entwistle and McCune 2004; Laurillard 1997; Ramsden 1997; Richardson 1994; Van Rossum and Hamer 2010; Watkins 1983). It has been widely recognized that the important distinction between these two approaches lies in the students' presence or absence of an intention to understand (Biggs 1987; Entwistle 2009; Kember 1996; Richardson 2000). Results of studies with Asian learners, particularly Chinese, point towards the existence of what Kember (1996) called a 'narrow' approach, which is characterized both by the intention to understand as well as memorise. Research with Chinese students has also shown that the dividing line for them doesn't fall between memorization and understanding, but between mechanical memorization and memorization to assist development in meaning (Kember and Gow 1990; Marton et al. 2005; Sachs and Chan 2003). Vermunt and Verloop (2000) also raised the possibility of the existence of cultural differences in the interrelations between students' learning strategies, views and motives. Subsequently, Vermunt and Vermetten (2004), in their review of research conducted with a particular research instrument, the Inventory of Learning Styles (ILS), observed that aspects of learning styles or patterns that Dutch university students experience as separate, could well go together among Indonesian students. Recently, Law (2009) made a similar observation with a group of Hong Kong post secondary education students using the Chinese version of the ILS.

This Asian learning pattern has often been referred to as 'the Asian paradox' (Kember 1996). This phrase reveals the strong theoretical assumptions that have emanated from the first findings on student learning patterns in Western societies. Those patterns nicely accommodated bipolar constructs such as surface-deep, internal-external, intrinsicextrinsic. Yet, studies on differences between Western and Asian cultures suggest that student learning patterns may be connected to the power distance, uncertainty avoidance, collectivism and masculinity of local cultures (e.g. Puong-Mai et al. 2006).

Conceptual equivalence refers to the degree to which constructs that are measured are the same in different cultures (Poortinga 1989). As a measure of conceptual equivalence Watkins and Akande (1994) used the similarity of factor structures in two cultures. Emics and etics are abstract concepts used to explain culture specific and universal phenomena, respectively. Emics are culture specific concepts, they apply in a particular culture and no a priori claim is made that they apply in another culture. Etics are culture invariant concepts or universals, they apply to more than one culture (Ho and Wu 2001). In crosscultural research emic and etic approaches may be combined so that emic ways of measuring constructs are developed and validated. An example of this approach is the 
three-step approach suggested by Berry (1990). In this approach, first existing descriptive categories and concepts are applied tentatively as an imposed etic. Then these are modified so that they represent an adequate emic description from within each system. Finally, shared categories can be used to build up new categories valid for both systems as a derived etic, which can be expanded if desired, until they constitute a universal. Thus, according to Ho and Wu (2001), emically defined constructs can be used in making crosscultural comparisons.

\section{The context of the present studies}

The term 'Asian' may mean different things in different countries. In the United States, the term is often used to refer to people from the countries that lie along the Pacific Ocean, including the island countries of the Pacific. In the United Kingdom, the term is normally used to refer to people from the Indian subcontinent (South Asia), while in Australia the term is normally used to refer to people from East and South-East Asia. In this article, the term 'Asian' will merely be used in a geographical sense to refer to people from the Asian continent.

The present study resulted from international exchange and cooperation of the very kind that was described in the opening sentences of this article. The aim of the study is to compare and contrast the learning patterns of higher education students in different continents, more specifically in Asia and Europe. Moreover, since the research literature has come up with rather stereotype descriptions of the Asian learner, we want to compare the students' learning patterns between two different Asian countries. Although Indonesia and Sri Lanka both are Asian countries, there are differences in their educational systems as well. The Sri Lankan educational system was dominated for a long time by the British system, while the Indonesian educational system has gone through a more autonomous development, although it has been influenced by the Dutch. One more reason to select Sri Lanka, Indonesia and The Netherlands for inclusion in this article was that, as a result of the international exchange and cooperation mentioned above, separate studies were available that had used the same diagnostic tool to research student learning patterns in these three countries.

Cultural differences between countries may lead to different patterns of learning and use of learning activities. Kember and Gow (1990) made an interesting observation that documented goals of higher education are remarkably similar across different national systems of higher education regardless of the cultural setting. Typically, these goals include the promotion of independent learning and critical thinking. One could also argue that these represent characteristics of the ideal student adjudged by the higher education system. Although it is often stated that universities must help students to master higher levels of competencies like relating, structuring and critical judgment, in practice, overreliance on lectures as a method of instruction is observed in the Sri Lankan context. As Trigwell and Prosser (2004) have shown, teachers' approaches to teaching are strongly associated with their students' approaches to learning. In Sri Lanka, at examinations students are required to reproduce the information and knowledge transmitted in the classroom considerably, despite the fact, that this practice is being criticized in many instances. On the other hand, the situation is deemed to improve as the students advance, as higherlevel thinking is not emphasized in the first year where the thrust is on teaching the basic concepts of the discipline.

"Guruvaraya" or teacher in Sri Lankan society is a reliable, respected person. This term "guru" is derived from the Sanskrit word meaning "weighty" or "honorable". In India, 
Sri Lanka as well as Indonesia, this is what a teacher is called (Ajisuksmo 1996; Hofstede 2001). It is a custom to respect, listen to, often not to criticize or challenge one's teacher. Therefore, students will rather obey and follow their teachers. Marambe (2007) asked students to describe an ideal student and several of them mentioned "a person who respects teachers", or, to quote one student: "Somebody who respects the teachers, a simple calm person, studies without grumbling. Always concerned about the teachers and try to make the teachers happy". This same student when asked to describe the characteristics of an ideal student, reported: "I think a student must respect his/her teachers... If they have doubts about their teachers then you cannot believe or learn from them. It is important to develop a good impression about the teachers" (Marambe 2007). The Sri Lankan secondary education system, although it has undergone many changes, is still a teacher centred and authoritarian system where the student is not supposed to argue or challenge the thinking process of the teacher.

The observation that Asian culture discourages the expression of thought is found to be valid even today. Impact of the family on shaping beliefs and practices is extremely strong and programs set in childhood are quite difficult to change. Subsequently children develop their practices while in school. It is seen that the pair teacher-student is replacing the role pair parent-child, but basic values and behaviours are carried forward from one sphere into the other. As described by Hofstede (2001), in countries where there is a large power distance situation such as in Sri Lanka, the parent-child inequality is perpetuated by the teacher-student relationship. Teachers are treated with utmost respect, older teachers more than younger teachers. It is commonly seen that students stand up when a teacher enters a classroom. Teachers often outline the intellectual paths to be followed. In the classroom there is a strict order where the teacher initiates the communication etc. A dominance of a factual view of knowledge among teachers and learners can be seen as a domination of its cultural context.

As opposed to the situation in low power distance (PDI) countries i.e. The Netherlands, in high PDI countries the educational process is highly personalized. What is transferred is not seen as impersonal "truth" but as the personal wisdom of the teacher. On the same line, Puong-Mai et al. (2006) reported that students of Confucian heritage cultures (e.g. China, Japan, Vietnam, Malaysia, Singapore etc.) rarely dare to question teachers. This has led to authoritarian behaviour of teachers and veneration of teachers by the students. As a result students, even if they disagree with the teachers, avoid arguing with them. In such learning environments, opportunities to enhance critical thinking skills become limited.

\section{A family of instruments on student learning patterns}

It is often difficult to find instruments to measure a particular construct across cultures. Indeed, it is questionable to assume cross-cultural equivalence of the conceptualization of what an instrument intends to measure. For the construct of student learning patterns, the Inventory of Learning Styles (ILS) (Vermunt 1994, 1998) and adapted translated versions of the ILS, the Inventarisasi Cara Belajar (ICB; Ajisuksmo 1996) and the Adyayana Rata Prakasha Malawa (ARPM; Marambe 2007) are reported to be valid candidates for assessing aspects of student learning patterns across different cultures (Marambe 2007).

The $I L S, I C B$ and $A R P M$ belong to a family of inventories that explore the interrelationships of students' use of cognitive and metacognitive learning strategies, their conceptions of learning and their learning orientations. A learning pattern is conceived as defined by a student's position on four learning components: processing strategies, regulation strategies, conceptions of learning and learning orientations. The ICB and ARPM are 
adapted, validated native language versions of the ILS. The ILS has been used to explore the learning patterns of first year Dutch university students in a number of studies (see e.g. Vermunt and Vermetten 2004; Vermunt 2005), while the $I C B$ has explored the learning styles of first year Indonesian university students in several fields of study (Ajisuksmo 1996; Ajisuksmo and Vermunt 1999). Subsequently, the ARPM was used to explore the learning patterns of Sri Lankan students in the Faculty of Medicine of the University of Peradeniya. It has been shown that the ILS, which was developed in the Netherlands, could be adequately adapted to identify learning patterns of Indonesian students (Ajisuksmo and Vermunt 1999) and Sri Lankan students (Marambe 2007; Marambe et al. 2009). Therefore, the instrument allows to compare aspects of student learning across different and similar cultures. In the following section, the three studies that will be compared in the present article will be described shortly. In Table 1, the scales of the ILS and their content are described.

The Dutch study: Learning patterns of first year Dutch university students using the ILS

In the Dutch study (Vermunt 1998), the ILS has been administered to 795 first-year regular university students of law, economics, sociology, psychology, and arts in the Netherlands. The mean age of these students was 22.5 years while $56 \%$ were males and $44 \%$ were females. In the Dutch study mailed back responses were considered. Participation had been voluntary. 22 of the 24 main and subscales of the ILS had reliabilities of .60 or higher (see Table 2). Results of a factor analysis on scale level showed four factors, that were interpreted as representing four different learning patterns: meaning directed learning, reproduction directed learning, application directed learning and undirected learning (Vermunt 1998).

The Indonesian study: Learning patterns of first year Indonesian university students using the ICB

The ICB was administered to 888 first year students, in the fields of management, accountancy, law, business administration, electrical engineering and mechanical engineering of the Atma Jaya University in Indonesia (Ajisuksmo and Vermunt 1999). The inventory had been completed during regular lecture time thus students were obliged to participate. Of the 24 main and subscales 18 had reliabilities of .60 or higher (see Table 2).

The Sri Lankan study: Learning patterns of first year Sri Lankan university students using the ARPM

The adapted version of the ILS, the ARPM, was administered to 144 out of 175 first year students of the Faculty of Medicine, University of Peradeniya at the end of a scheduled lecture (Marambe 2007). Mean age of these students was reported as 22 years while $51 \%$ were males and $49 \%$ were females. Of the 24 main and subscales, 18 had reliabilities of 60 or higher (see Table 2). In this study there was a larger sample of 582 students who had completed the ARPM. However, these students came from different study years: new entrants, and first, third and fourth year students. Since the Dutch and Indonesian studies only had first year participants, we felt it to be more appropriate to include only the first year Sri Lankan students for the comparative purposes. 
Table 1 Scales of the inventory of learning styles (ILS) and their content

\section{Parts and scales of the Description of content}

ILS

\section{Processing strategies}

Deep processing

Relating and structuring

Critical processing

Stepwise processing

Memorising and rehearsing

Analysing

Concrete processing

\section{Regulation strategies}

Self-regulation

Learning process and results

Learning content

External regulation

Learning process

Learning results

Lack of regulation

Conceptions of learning

Construction of knowledge

Intake of knowledge

Use of knowledge

Stimulating education

Co-operative learning

\section{Learning orientations}

Personally interested

Certificate-oriented

Self-test-oriented

Vocation-oriented

Ambivalent
Relating elements of the subject matter to each other and to prior knowledge; structuring these elements into a whole.

Forming one's own view on the subjects that are dealt with, drawing one's own conclusions, and being critical of the conclusions drawn by textbook authors and teachers.

Learning facts, definitions, lists of characteristics and the like by heart by rehearsing them.

Going through the subject matter in a stepwise fashion and studying the separate elements thoroughly, in detail and one by one.

Concretising and applying subject matter by connecting it to one's own experiences and by using what one learns in a course in practice.

Regulating one's own learning processes through regulation activities like planning learning activities, monitoring progress, diagnosing problems, testing one's results, adjusting, and reflecting.

Consulting literature and sources outside the syllabus.

Letting one's own learning processes be regulated by external sources, such as introductions, learning objectives, directions, questions or assignments of teachers or textbook authors.

Testing one's learning results by external means, such as the tests, assignments, and questions provided.

Monitoring difficulties with the regulation of one's own learning processes.

Learning viewed as constructing one's own knowledge and insights. Most learning activities are seen as tasks of students.

Learning viewed as taking in knowledge provided by education through memorising and reproducing; other learning activities are tasks of teachers.

Learning viewed as acquiring knowledge that can be used by means of concretising and applying. These activities are seen as tasks of both students and teachers.

Learning activities are viewed as tasks of students, but teachers and textbook authors should continuously stimulate students to use these activities.

Attaching a lot of value to learning in co-operation with fellow students and sharing the tasks of learning with them.

Studying out of interest in the course subjects and to develop oneself as a person.

Striving for high study achievements; studying to pass examinations and to obtain certificates, credit points, and a degree.

Studying to test one's own capabilities and to prove to oneself and others that one is able to cope with the demands of higher education.

Studying to acquire professional skill and to obtain a (nother) job.

A doubtful, uncertain attitude toward the studies, one's own capabilities, the chosen academic discipline, the type of education, etc. 
Table 2 Internal consistencies (Cronbach $\alpha$ ) and number of items per scale of Sri Lankan (ARPM, $\mathrm{N}=144$ ), Dutch (ILS, $\mathrm{N}=795$ ) and Indonesian (ICB, $\mathrm{N}=888$ ) samples (Dutch ILS results adapted from Vermunt 1998; Indonesian ICB results adapted from Ajisuksmo 1996)

\begin{tabular}{|c|c|c|c|c|c|c|}
\hline Inventory Scale & $\alpha \operatorname{ILS}$ & $\mathrm{N}$ items & $\alpha$ ARPM & $\mathrm{N}$ items & $\alpha \mathrm{ICB}$ & $\mathrm{N}$ items \\
\hline \multicolumn{7}{|l|}{ Processing strategies } \\
\hline Deep processing & .85 & 11 & .83 & 11 & .83 & 11 \\
\hline Relating and structuring & .83 & 7 & .75 & 7 & .76 & 7 \\
\hline Critical processing & .72 & 4 & .73 & 4 & .69 & 4 \\
\hline Stepwise processing & .78 & 11 & .65 & 11 & .73 & 11 \\
\hline Memorising and rehearsing & .79 & 5 & .56 & 5 & .58 & 5 \\
\hline Analysing & .63 & 6 & 60 & 6 & .62 & 6 \\
\hline Concrete processing & .71 & 5 & .77 & 5 & .64 & 5 \\
\hline \multicolumn{7}{|l|}{ Regulation strategies } \\
\hline Self-regulation & .79 & 11 & .73 & 11 & .78 & 11 \\
\hline Learning process and results & .73 & 7 & .68 & 7 & .74 & 7 \\
\hline Learning content & .73 & 4 & .50 & 4 & .68 & 4 \\
\hline External regulation & .68 & 11 & 69 & 11 & .68 & 11 \\
\hline Learning process & .48 & 6 & .49 & 6 & .68 & 6 \\
\hline Learning results & .65 & 5 & 69 & 5 & .59 & 5 \\
\hline Lack of regulation & .72 & 6 & .66 & 6 & .61 & 6 \\
\hline \multicolumn{7}{|l|}{ Conceptions of learning } \\
\hline Construction of knowledge & .77 & 9 & .73 & 9 & .53 & 9 \\
\hline Intake of knowledge & .78 & 9 & .66 & 13 & .74 & 9 \\
\hline Use of knowledge & .70 & 6 & .74 & 9 & .66 & 6 \\
\hline Stimulating education & .88 & 8 & .66 & 9 & .82 & 8 \\
\hline Cooperative learning & .89 & 8 & .67 & 8 & .67 & 8 \\
\hline \multicolumn{7}{|l|}{ Learning orientations } \\
\hline Personally interested & .57 & 5 & .55 & 5 & .22 & 5 \\
\hline Certificate-oriented & .76 & 5 & 63 & 5 & .62 & 5 \\
\hline Self-test-oriented & .84 & 5 & .58 & 5 & .55 & 5 \\
\hline Vocation-oriented & .69 & 5 & .50 & 5 & .46 & 5 \\
\hline Ambivalent & .82 & 5 & .68 & 7 & .64 & 5 \\
\hline
\end{tabular}

All three studies have been conducted in the context of traditional, lecture-based university teaching methods (Vermunt 2007). Although especially many medical schools nowadays have adopted innovative teaching methods like problem-based learning or casebased teaching, at the time these studies were conducted this was not the case at all universities and schools included in this study, including the medical school of the Sri Lankan study.

The present study

These three large-scale studies provide us with an excellent opportunity to investigate cross-cultural differences between two Asian cultures and one Western. Thus, the present meta-analysis of the Sri Lankan, Indonesian and Dutch studies aims at examining similarities and differences in the reported use of learning strategies, learning conceptions and 
learning orientations, and in factor structures among three culturally different groups of first year university students. More specifically, the following research questions will be investigated:

1. Do Sri Lankan, Dutch and Indonesian students differ from each other in terms of the reported use of learning strategies, conceptions of learning and learning orientations, as assessed by the ARPM, ILS and ICB?

2. What are the similarities and differences between Sri Lankan, Dutch and Indonesian students in the interrelations among their learning strategies, conceptions of learning and learning orientations as expressed in the factor structures identified by the ARPM, ILS, and ICB?

\section{Method}

A meta-analysis was performed on the results of the studies done by Vermunt (1998) in the Netherlands, Ajisuksmo and Vermunt (1999) in Indonesia, and Marambe (2007) in Sri Lanka. All three studies investigated learning strategies, conceptions and orientations of first year university students and used a validated native version of the same questionnaire, the ILS. In all three studies the same 120-item version of the ILS had been used. The Indonesian version of the ILS, the ICB, contains exactly the same 120 items as the original Dutch version. The Sri Lankan version contains the same 120 items as well, only here a few items were added to some scales to increase scale reliabilities. However, in all subsequent analyses done, scale totals were divided by the number of items in a scale so means could be compared.

Comparison of the internal consistency values of the three instruments showed that the internal consistencies of most of the scales of the ICB were quite high and comparable to those of the ILS (Table 2). Only in the domain of learning orientations (more specifically, personally interested and vocation oriented), these internal consistencies were generally lower than those obtained with Dutch students. Similarly, internal consistencies of most of the scales of the ARPM were high and comparable to findings with the ILS. Although the scale external regulation of process showed a low alpha value, the value of the external regulation scale was acceptable.

The mean scale scores of the three groups of students were compared by ANOVA, based on the published mean scale scores and standard deviations (Soper 2011). Bonferroni corrections were applied to correct for the number of significance tests ( $\mathrm{p}$ divided by the number of scales). In case of significant differences between groups, Scheffé post hoc analyses (Wendorf 2004) were performed to identify which of the groups differed from each other.

Next, similarities and differences in the factor structures of learning patterns were investigated. For each sample, principal component analysis followed by Varimax rotation had been performed to extract four factors. Since the meta-analysis was based on the published factor loadings, and the non-salient loadings were not reported in those original studies, we were not able to apply more rigorous statistical techniques to quantify the similarity between the factor structures (e.g. Tabachnick and Fidell 2001). Therefore, we applied a more qualitative comparison of the factor loadings and structures. The extracted factor structures of the three samples were compared by inspecting high positive and negative loadings on these factors. 


\section{Results}

In Table 3, the means and standard deviations on the ILS-, ARPM- and ICB-scale scores of the three samples are depicted, as well as the F-values and significance levels of the differences between the means. When a Bonferroni correction was applied correcting for the number of tests (p divided by 18), on 15 of the 18 scales significant differences showed up between the three samples. The differences on the scales analysing, external regulation and personal interest were not significant. Post hoc Scheffé tests, again correcting for the number of tests, revealed that most differences showed up between Indonesian and Dutch students, on 15 of the 18 scales.

Table 3 Means (M) and standard deviations (SD) on ILS, ARPM, and ICB scales of Dutch (NL), Sri Lankan (SL) and Indonesian (IN) samples, F-values and significance levels of the differences between the means based on analysis of variance

\begin{tabular}{llllll}
\hline Inventory scale & $\mathrm{NL}$ & $\mathrm{SL}$ & $\mathrm{IN}$ & $\mathrm{F}$ & $p$ \\
& $\mathrm{M}(\mathrm{SD})$ & $\mathrm{M}(\mathrm{SD})$ & $\mathrm{M}(\mathrm{SD})$ & $(2,1824)$ & \\
\hline
\end{tabular}

Processing strategies

Deep processing

Relating and structuring

Critical processing

Stepwise processing

Memorising and rehearsing

Analysing

Concrete processing

Regulation strategies

Self-regulation

Learning process and results

Learning content

External regulation

Learning process

Learning results

Lack of regulation

Conceptions of learning

Construction of knowledge

Intake of knowledge

Use of knowledge

Stimulating education

Cooperative learning

Learning orientations

Personally interested

Certificate-oriented

Self-test-oriented

Vocation-oriented

Ambivalent

$\begin{array}{ll}3.36(1.18) & 3.17(.77) \\ 2.81(1.25) & 2.32(.87)\end{array}$

$2.83(1.30)$

2.73 (1.16)

2.81 (1.17)

$2.30(1.19)$

$3.22(1.22) \quad 3.11(.60) \quad 3.19(1.53)$

$2.40(1.17)$

$3.53(1.10) \quad 3.93(.50)$

$3.52(.99)$

3.13 (1.13)

$3.01(1.20)$

$3.17(1.04) \quad 3.44(.63)$

$3.28(1.18)$

2.83 (1.28)

3.79 (1.07)
$2.56(1.61)$

72.03

2.18 (1.34)

52.64

$2.41(.73)$

3.33 (1.69)

38.52

$3.02(.68)$

2.92 (1.57)

5.47

$3.19(.87)$

2.99 (1.37)

7.77

2.75 (.67)

$2.76(1.67)$

23.52

2.65 (1.36)

12.57

$2.84(.79)$

$4.12(.86)$

81.16

4.14 (1.04)

84.03

$3.74(.45)$

4.57 (.46)

191.39

3.17 (1.45)

17.39

$3.80(.77)$

3.82 (1.12)

114.38

3.85 (.91)

3.33 (1.30)

5.78

3.39 (1.18)

3.96 (1.23)

69.67

$3.41(.72)$

4.12 (1.09)

262.60

$4.10(.79)$

$4.43(.75)$

104.72

2.79 (1.82)

**** *** $* * *$ $* *$ *** $*$ $2.84(.77)$

$* p<.05, * * p<.01, * * * p<.001$ (with Bonferroni correction) 
Comparing the findings in the Dutch and the Sri Lankan studies the following was found. Significant differences between Sir Lankan and Dutch students showed up on 13 scales. Concerning learning strategies, Sri Lankan students scored lower on critical processing and memorising, and higher on concrete processing, self-regulation and lack of regulation than Dutch students. In their conceptions of learning, Sri Lankan students viewed learning more as construction of knowledge, intake of knowledge, use of knowledge, stimulating education and cooperative learning than Dutch students. In their learning orientations, Sri Lankan students reported to be more self-test oriented, vocation-oriented and ambivalent than Dutch students.

Between Sri Lankan and Indonesian students, significant differences showed up on 8 of the 18 scales. The mean scale scores between Sri Lankan and the Indonesian students were significantly different for two of the five processing scales. The Sri Lankan students more often reported the use of relating and structuring strategies, while the Indonesian students reported the use of memorising and rehearsing strategies more often. No difference was found on any of the regulation scales between the two Asian groups. In their learning orientations, Sri Lankan students reported to be less certificate-oriented, self-test-oriented and vocation-oriented than Indonesian students. On the conceptions of learning scales, Indonesian students scored higher on intake of knowledge and use of knowledge; Sri Lankans endorsed stimulating education significantly more.

Between Indonesian and Dutch students, the post hoc Scheffé tests revealed significant differences on 15 of the 18 scales. Concerning learning strategies, Indonesian students reported to make more use of memorising and concrete strategies and less use of relating and structuring, and critical strategies than Dutch students. Moreover, they had higher scores on self-regulation and lack of regulation than Dutch students. In their conceptions of learning, Indonesian students viewed learning more as construction of knowledge, intake of knowledge, use of knowledge, and cooperative learning than Dutch students. In their learning orientations, Indonesian students were more certificate-oriented, self-test oriented, vocation-oriented and ambivalent than Dutch students.

In Table 4, similarities and differences in the factor structures of learning patterns between the Sri Lankan, Indonesian and Dutch studies are shown. These similarities and differences will be described per factor. Overall, rather similar patterns emerged when the Dutch, Indonesian and Sri Lankan studies were compared. The total amount of explained variance differed only $2.2 \%$ (52.5, 53.7 and $54.7 \%$, respectively).

The first factor of the Sri Lankan study was characterised by high loadings of four processing strategies, relating and structuring, critical processing, analysing and concrete processing, and the two self-regulation strategies, and moderate loadings of a personally interested learning orientation and the conception of learning in which construction of knowledge is emphasized. It can be interpreted as a meaning directed learning pattern. The structure of the meaning directed factor of the Dutch and Sri Lankan studies was quite similar, although the Sri Lankan factor had some extra loadings of external regulation of learning results and of an analyzing strategy, and the negative loading of certificateorientation was absent. The structure of the Indonesian meaning directed factor was more different. The differences pertained to the presence of loadings of the memorizing and rehearsing strategy and of the two external regulation scales, and the absence of a loading of personal interest.

The second factor of the Sri Lankan study, which can be interpreted as a reproduction directed learning pattern, was characterized by high or moderate loadings of the processing scales memorising and rehearsing, and analyzing, the two external regulation scales, intake of knowledge as the learning conception, and three of the learning orientation scales, 
Table 4 Factor loadings of ILS scales in a 4-factor Varimax solution for Dutch (NL, N = 795), Sri Lankan (SL, $\mathrm{N}=144$ ) and Indonesian (IN, $\mathrm{N}=888$ ) students (principal component analysis; loadings $>-.25$ and $<.25$ omitted)

\begin{tabular}{|c|c|c|c|c|c|c|c|c|c|c|c|c|}
\hline \multirow[t]{2}{*}{ Inventory scales } & \multicolumn{3}{|c|}{ Factor 1} & \multicolumn{3}{|c|}{ Factor 2} & \multicolumn{3}{|c|}{ Factor 3} & \multicolumn{3}{|c|}{ Factor 4} \\
\hline & NL & SL & IN & NL & SL & IN & NL & SL & IN & NL & SL & IN \\
\hline
\end{tabular}

Processing strategies

Deep processing

$\begin{array}{llll}\text { Relating and structuring } & .73 & .85 & .82\end{array}$

$\begin{array}{llll}\text { Critical processing } & .71 & .78 & .72\end{array}$

Stepwise processing

Memorising and

rehearsing

Analysing

Concrete processing

$\begin{array}{lllll}67 & .69 & .74 & .74\end{array}$

Regulation strategies

Self-regulation

$\begin{array}{lllllll}\text { Learning process and } & .74 & .77 & .77 & & & \\ \text { results } & & & & & & \\ \text { Learning content } & .71 & .50 & .68 & & & \\ \text { External regulation } & & & & & & \\ \text { Learning process } & & & .47 & .72 & .69 & .59 \\ \text { Learning results } & & .41 & .61 & .57 & .54 & .36\end{array}$

Lack of regulation

Conceptions of learning

Construction of knowledge

Intake of knowledge

Use of knowledge

Stimulating education

Cooperative learning

Learning orientations

Personally interested

$\begin{array}{rr}.52 & .41 \\ -.40 & \end{array}$

Certificate-oriented

$-.40$

$\begin{array}{lll}.74 & .36 & .48\end{array}$

$.75 \quad .55$

$-.41$

Self-test-oriented

$-.38 \quad-.29$

$\begin{array}{lll}60 & .56 \quad .54\end{array}$

$.44 \quad .52$

.26

.74

$.75 \quad .59$

$.68 \quad .62$

Vocation-oriented

Ambivalent

$-.26$

$\begin{array}{rrr}.46 & .45 & . \\ .59 & .67 & .36 \\ .52 & .47 & \\ .56 & .37 & .80\end{array}$

$.53 \quad .69 \quad .62$

namely certificate-oriented, vocation-oriented and self-test oriented. Apart from the moderate loadings of the vocation-oriented and self-test oriented learning orientations, the defining features of this learning pattern were the same as in the Dutch study. The structure of the Indonesian reproduction directed factor was similar as well, although this factor showed a loading of personal interest and an absence of a loading of the analysing scale.

The third factor of the Sri Lankan and the Indonesian studies were quite similar and showed high or moderately high loadings almost exclusively of all learning conception scales. This factor can be interpreted as a passive idealistic learning pattern. A similar factor did not show up among the Dutch students. Instead, in the Dutch study a discrete 
application directed learning pattern showed up, characterized by concrete processing, use of knowledge as a learning conception, and a vocational learning orientation.

The fourth factor of the Sri Lankan study was characterised by high loadings of lack of regulation and an ambivalent orientation, and a moderate inverse loading of a personally interested learning orientation. This factor can be interpreted as representing an undirected learning pattern. In all three studies an undirected factor showed up, characterized by high loadings of the scales lack of regulation and an ambivalent learning orientation. In the Dutch study, this factor also showed high loadings of the learning conceptions stimulating education and cooperative learning, but these were absent in the other two studies. In the Indonesian study, there was a moderate inverse loading of a vocational orientation on this factor.

\section{Conclusions and discussion}

The objective of this meta-analysis was to identify the similarities and differences in the reported learning strategies, learning conceptions, learning orientations and the internal structure of the learning patterns among a group of European students and the two Asian student groups.

The first research question was: Do Sri Lankan, Dutch and Indonesian students differ from each other in terms of the reported use of learning strategies, conceptions of learning and learning orientations? This question can be answered affirmatively. The Sri Lankan and the Dutch groups of students differed significantly on thirteen of the eighteen scales. Sri Lankan students had lower scores on critical processing and memorising, and higher scores on concrete processing, self-regulation and lack of regulation of learning than Dutch students. In depth interviews conducted by Marambe (2007), yielded supportive evidence for this kind of learning behaviour. Moreover, they scored higher on all five conceptions of learning scales and on the learning orientations scales self-test oriented, vocation-oriented and ambivalent. The Sri Lankan and Indonesian students scored differently on eight of the eighteen scales: two of the processing strategies, three learning orientations and three conceptions of learning. Sri Lankan students reported the use of memorizing and rehearsing strategy less often while they reported the use of relating and structuring strategy more often than Indonesian students. Moreover, Sri Lankan students reported to be less certificate-oriented, self-test-oriented and vocation-oriented than Indonesian students. In their conceptions of learning, Sri Lankan students attached more value to stimulating education and viewed learning less as intake of knowledge and use of knowledge than Indonesian students. There were no differences between the three groups regarding the use of an analysing strategy, external regulation of learning and studying out of personal interest. Thus, it is interesting to note that in all cultures, despite differences in teaching and assessment, the scores for external regulation strategies appeared to be similar.

In summary, there were more differences in learning patterns between Sri Lankan and Dutch students than between Sri Lankan and Indonesian students. On the other hand, on almost half of the scales there were differences between the Sri Lankan and Indonesian students. The Asian learner turned out to be a myth.

The second research question referred to similarities and differences in the internal structure of learning patterns observed in the two Asian and the Western studies. In all three cultural samples four factors could be extracted. The internal structure of three of them shared some common features. These were the meaning directed leaning pattern with loadings of the deep processing strategies and self regulation, personal interest and 
construction of knowledge, the reproduction directed learning pattern with loadings of stepwise processing strategies, external regulation, certificate orientation and intake of knowledge, and the undirected learning pattern with loadings on lack of regulation and ambivalence. Both Asian studies did not show a clear, distinct application directed pattern that has been repeatedly reported by a number of Dutch investigations on university students in the first year of their studies, characterised by concrete processing, use of knowledge and a vocational orientation (Vermunt and Vermetten 2004). Instead, in both Asian groups one of the factors was defined almost exclusively by conceptions of learning and was interpreted as a passive-idealistic learning pattern.

It is interesting to note that despite the fact that the two Asian groups were from different disciplines (e.g. medical and non-medical), the interrelations between learning dimensions shown in the two Asian samples had many similarities. A previous European study in which the ILS was used among medical and non-medical students had yielded similar results (Lonka and Lindblom-Ylänne 1996). Besides these similarities, there were differences in the internal structure of learning patterns as well. For example, in the Sri Lankan study the meaning directed factor was not characterized by high or moderately high loadings of external regulation and reproductive elements as was observed by Ajisuksmo and Vermunt (1999). It is interesting that, unlike in the Dutch sample, reproduction directed learning was characterized by high loadings of personally interested and vocational learning orientations in the Indonesian sample, and by high loadings of vocational orientation in the Sri Lankan sample. Unlike the Dutch study, the undirected learning pattern showed an inverse loading of a personally interested learning orientation in the Sri Lankan study and a loading of a vocational orientation in the Indonesian sample.

Cultural differences and similarities between the three countries as well as disciplinary differences between the groups of students can be brought in as explanatory factors for some of the differences that showed up. For example, Lonka and Lindblom-Ylänne (1996) compared Finnish psychology students and medical students and found that application directed learning was more typical of medical students. Subsequently, Lindblom-Ylänne and Lonka (2000) showed that application directedness is an important dimension among advanced students. Similarly, Vermunt and Vermetten (2004) concluded that application directed learning emerges relatively late as a distinct learning dimension in university students' development as a learner. Thus, the absence of an application directed learning pattern among the Sri Lankan medical students could probably be due to the fact that these are first year students. Nevertheless, this may also reflect basic socio-cultural differences between Asians and Europeans.

Noteworthy is the fact that all factors in the Dutch sample (Vermunt 1998) were defined by loadings of at least three learning components. This may indicate associations between the learning strategies students use and their learning conceptions and orientations. In other words, learning activities employed by the Dutch students were guided or regulated by their views on learning and their motives for studying. The Sri Lankan sample did demonstrate these associations or interrelations between different learning components in two of the four factors. In the present study such conceptual consonance was shown in the meaning directed dimension (factor 1) and reproduction dimension (factor 2). Thus, there was evidence of the loadings of factors of the Sri Lankan study (e.g. meaning directed learning, reproduction directed learning and undirected learning) being spread over different domains of learning, though it was not to the same extent as the Dutch study, whereas in the case of Indonesian students coherence among learning components were less. Nhan (2006), using the Vietnamese version of the ILS, made a similar observation that among Vietnamese medical students internal associations between learning components were less strong, suggesting the 
possibility that Asian students' learning activities are more under control of the learning environment than being regulated by own motives and views.

As pointed out by Ajisuksmo and Vermunt (1999), the other important difference confirmed by the present study is that the elements within a learning component generally showed high loadings on the same factor, while in the Dutch sample these loadings spread over different factors. The passive idealistic dimension is a good example. The presence of such different patterns among first year students could on the one hand be explained as a cultural variation. On the other hand it can be viewed as a transitional phenomenon, as suggested by Lindblom-Ylänne and Lonka (2000), Vermunt and Minnaert (2003), and Vermunt and Vermetten (2004). Students may experience a mismatch between the learning strategies the learning environment fosters and the learning strategies they habitually use. Given the facts that the school education system in Sri Lanka is a teacher centred one and the medium of instruction in the university abruptly changes, students may experience the first year at the university as a very different learning context. As discussed by Vermunt and Verloop (1999), this kind of 'friction' between teaching and learning strategies at the onset of university life may be constructive in nature thus leading to the development of mature learning conceptions and learning practices or the other way round. However, further explanations are beyond the scope of the present investigation.

It is unarguable that some Sri Lankan teachers need to improve their skills in conducting tutorials to enable students to understand and thereby promote conceptual changes. It appears that the Asian thinking has many similarities, as the Indonesian society too shares a somewhat same line of thinking (Ajisuksmo and Vermunt 1999). In a way, Yang, Zheng and Li (2006) are right in reporting that a strong influence of the Confucian philosophy is observed in many Asian countries. In the view of some Sri Lankan communities, grades (end result) are more important than the learning process. Within the higher education context, it is a pity that only some teachers attempt to develop critical thinking skills and argument among their students. Teachers are mostly interested about the content of subject matter, and much less in how students process the information, what strategies they use in comprehending subject matter, and how they may regulate their students' learning process and understanding.

In this regard, it is interesting to note that the Sri Lankan students had lower scores on memorising and rehearsing than both the Dutch and the Indonesian students. The Asian culture obviously cannot be an explanatory factor for this remarkable outcome of the present study. This along with the relatively higher scores reported for concretising and analysing strategies suggests that Sri Lankan students do engage in some degree of understanding and meaningful learning.

Another prominent feature of the "Asian culture" is the paternalistic attitudes of parents. According to Marambe (2007), some of the Sri Lankan students mentioned that they were not given the choice to select their field of study. In some cases they indicated that parents, family members or teachers influenced their career choices. The interviews conducted in a pilot study (Marambe 2007) revealed that 38\% of the medical students indicated that their parents or other family members had influenced them directly or indirectly in making the career choice. This is a similar percentage to what Ajisuksmo and Vermunt (1999) have reported about students from Indonesia and their own choice of field of study. As pointed out by Ajisuksmo and Vermunt (1999), it is also possible that cultural factors would have led to much difficulty or confusion at the time students themselves have to think about their orientations to their studies. The high degree of ambivalent orientation among both Asian groups shown in this study seems to support this explanation.

Attention is also drawn to the fact that both Asian studies showed considerably higher scores on most of the learning conceptions and orientation scales while this was not the case 
for the pattern of scores for learning strategies. There is a possibility that the answering scale incorporated for conceptions of learning and learning orientations (i.e. from agree to disagree) had an impact on these responses. The respondents had to indicate the degree to which they agreed or disagreed with a statement as opposed to the part on strategies in which they had to indicate how frequently they did something. Maybe disagreeing with statements that come from an authority is more impolite in Asian than in Western culture (for a more elaborate discussion of variations in response style across different cultures see for example Chen et al. (1995) and Smith (2004)). This phenomenon would reflect the mean scale scores, but not the factor structures. Hence, both kind of comparisons (means and interrelations of scales) represent different but complementary perspectives on the similarities and differences in learning patterns of students from different countries and cultures.

An important direction for future research would be to study the changes in learning behaviour upon instructional changes. Since the instructional changes take a long time to have a reasonable impact on the learning process, they need to be studied over a longer period of time. There is also a place for studies on the effect of all kind of instructional measures and variables on learning patterns. The changes in learning pattern in the final year where the student is required to engage in self-directed learning and problem solving seems yet another useful area of investigation.

Contrary to the expectation that Asian learners have a propensity for rote learning, the Sri Lankan students reported the lowest score for memorising strategy and relatively high scores for concretising and analysing strategies. This could be indicative for the not so strong influence of culture on the use of learning strategies and thus powerful learning environments have a great potential in bringing about a change towards the greater use of more constructive learning strategies.

Although the way of learning students bring with them when they go studying abroad may conflict with what is demanded of them in the new educational environment, these patterns of learning are not fixed but changeable. Learning conceptions, orientations and strategies do not necessarily develop and change in the same pace, however. We must acknowledge that this change process may be painstaking and involve temporal frictions between what students believe in, want and actually do to learn. Adequate support geared at knowledge of students' learning patterns may help them develop their way of learning and bring their study views, motives and actions in a new balance again, an enriching result in itself of their experience abroad.

Open Access This article is distributed under the terms of the Creative Commons Attribution Noncommercial License which permits any noncommercial use, distribution, and reproduction in any medium, provided the original author(s) and source are credited.

\section{References}

Ajisuksmo, C. R. P. (1996). Self-regulated learning in Indonesian higher education. Doctoral thesis, Tilburg University, The Netherlands \& Atma Jaya Catholic University, Indonesia.

Ajisuksmo, C. R. P., \& Vermunt, J. D. (1999). Learning styles and self-regulation of learning at university: An Indonesian study. Asia Pacific Journal of Education, 19(2), 45-59.

Berry, J. W. (1990). Imposed etics, emics and derived etics: Their conceptual and operational status in crosscultural Psychology. In T. N. Headland, K. L. Pike, \& M. Harris (Eds.), Emics and etics: The insider/ outsider debate (pp. 84-99). Newbury Park, CA: Sage Publications.

Biemans, H., \& Van Mil, M. (2008). Learning styles of Chinese and Dutch students compared within the context of Dutch higher education in life sciences. The Journal of Agricultural Education and Extension, 14, 265-278.

Biggs, J. B. (1987). Student approaches to learning and studying. Melbourne: Australian Council for Educational Research. 
Charlesworth, Z. M. (2008). Learning styles across cultures: Suggestions for educators. Education \& Training, 50, 115-127.

Chen, C., Lee, S. Y., \& Stevenson, H. W. (1995). Response style and cross-cultural comparisons of rating scales among East Asian and North-American students. Psychological Science, 6(3), 170-175.

Clark, R., \& Gieve, S. N. (2006). On the discursive construction of 'the Chinese learner'. Language Culture and Curriculum, 19, 54-73.

Dahlin, B., \& Watkins, D. (2000). The role of repetition in the processes of memorising and understanding: a comparison of the views of German and Chinese secondary school students in Hong Kong. British Journal of Educational Psychology, 70, 65-84.

Entwistle, N. (2009). Teaching for understanding at university. Basingstoke: Palgrave Macmillan.

Entwistle, N., \& McCune, V. (2004). The conceptual bases of study strategy inventories. Educational Psychology Review, 16, 325-346.

Ho, D. Y., \& Wu, M. (2001). Introduction to cross-cultural Psychology. In L. L. Adler \& U. P. Gielen (Eds.), Cross-cultural topics in psychology (2nd ed., pp. 3-13). U.S.A.: Greenwood Publishing.

Hofstede, G. H. (2001). Culture's consequences: Comparing values, behaviours, institutions, and organizations across nations (2nd ed., pp. 1-77). California: Sage Publications.

Kember, D. (1996). The intention to both memorise and understand: Another approach to learning? Higher Education, 31, 341-354.

Kember, D. (2000). Misconceptions about the learning approaches, motivation and study practices of Asian students. Higher Education, 40, 99-121.

Kember, D., \& Gow, L. (1990). Cultural specificity of approaches to study. British Journal of Educational Psychology, 60, 356-363.

Kennedy, P. (2002). Learning cultures and learning styles: myth-understandings about adult (Hong Kong) Chinese learners. International Journal of Lifelong Education, 21, 430-445.

Laurillard, D. M. (1997). Styles and approaches in problem solving. In F. Marton, D. Hounsell, \& N. Entwistle (Eds.), The experience of learning (2nd ed., pp. 126-144). Edinburgh: Scottish Academic Press.

Law, D. C. (2009). The adaptation, validation and application of a research instrument for investigating the relationships between students' perceptions of the learning context and students' learning patterns in post secondary education in Hong Kong. Doctoral dissertation, University of Durham, UK.

Lindblom-Ylänne, S., \& Lonka, K. (2000). Dissonant study orchestrations of high-achieving university students. European Journal of Psychology of Education, 15, 19-32.

Lonka, K., \& Lindblom-Ylänne, S. (1996). Epistemologies, conceptions of learning and study practices in medicine and psychology. Higher Education, 31, 5-24.

Manikutty, S., Anuradha, N. S., \& Hansen, K. (2007). Does culture influence learning in higher education? International Journal of Learning and Change, 2, 70-87.

Marambe, K. N. (2007). Patterns of student learning in medical education-a Sri Lankan study in a traditional curriculum. Doctoral thesis, Maastricht University, The Netherlands.

Marambe, K. N., Edussuriya, D. H., Somaratne, P. D. I. S., \& Piyaratne, C. (2009). Do medical students who claim to be using deep learning strategies perform better at the Forensic medicine examination? South East Asian Journal of Medical Education, 3(1), 25-30.

Marton, F., Wen, Q., \& Wong, K. C. (2005). 'Read a hundred times and the meaning will appear...' changes in Chinese university students' views of the temporal structure of learning. Higher Education, 49, 291-318.

Nhan, V. T. (2006). Learning styles of medical students in University of Medicine and Pharmacy at HoChiMinh city. Master thesis, Maastricht University, The Netherlands.

Poortinga, Y. H. (1989). Equivalence of cross-cultural data: An overview of basic issues. International Journal of Psychology, 24, 737-756.

Puong-Mai, N., Terlouw, C., \& Pilot, A. (2006). Culturally appropriate pedagogy: the case of group learning in a Confucian heritage culture context. Intercultural Education, 17, 1-19.

Purdie, N., \& Hattie, J. (2002). Assessing students' conceptions of learning. Australian Journal of Educational \& Developmental Psychology, 2, 17-32.

Purdie, N., Hattie, J., \& Douglas, G. (1996). Student conceptions of learning and their use of self-regulated learning strategies: A cross-cultural comparison. Journal of Educational Psychology, 88, 87-100.

Ramsden, P. (1997). The context of learning in academic departments. In F. Marton, D. Hounsell, \& N. Entwistle (Eds.), The experience of learning (2nd ed., pp. 198-216). Edinburgh: Scottish Academic Press.

Richardson, J. T. E. (1994). Cultural specificity of approaches to studying in higher education: A literature survey. Higher Education, 27, 449-468. 
Richardson, J. T. E. (2000). Researching student learning. Buckingham, UK: Open University Press and SRHE.

Sachs, J., \& Chan, C. (2003). Dual scaling analysis of Chinese students' conceptions of learning. Educational Psychology, 23, 181-193.

Smith, P. B. (2004). Acquiescent response bias as an aspect of cultural communication style. Journal of Cross-Cultural Psychology, 35(1), 50-61.

Soper, D. (2011). Statistics calculators. http://www.danielsoper.com/statcalc/calc43.aspx.

Tabachnick, B. G., \& Fidell, L. S. (2001). Understanding multivariate statistics (4th ed ed.). Boston: Allyn and Bacon.

Trigwell, K., \& Prosser, M. (2004). Development and use of the approaches to teaching inventory. Educational Psychology Review, 16, 409-424.

Valiente, C. (2008). Are students using the 'wrong' style of learning? Active Learning in Higher Education, 9, 73-91.

Van Rossum, E. J., \& Hamer, R. (2010). The meaning of learning and knowing. Doctoral thesis, Utrecht University, The Netherlands. Rotterdam: Sense Publishers.

Vermunt, J. D. (1994). Inventory of learning styles in higher education. Tilburg: Tilburg University, Department of Educational Psychology.

Vermunt, J. D. (1998). The regulation of constructive learning processes. British Journal of Educational Psychology, 68, 149-171.

Vermunt, J. D. (2005). Relations between student learning patterns and personal and contextual factors and academic performance. Higher Education, 49, 205-234.

Vermunt, J. D. (2007). The power of learning environments to influence student learning. British Journal of Educational Psychology Monograph Series II, 4, 73-90.

Vermunt, J., \& Minnaert, A. (2003). Dissonance in student learning patterns: when to revise theory? Studies in Higher Education, 28, 49-61.

Vermunt, J. D., \& Verloop, N. (1999). Congruence and friction between learning and teaching. Learning and Instruction, 9, 257-280.

Vermunt, J. D., \& Verloop, N. (2000). Dissonance in students' regulation of learning processes. European Journal of Psychology of Education, 15, 75-87.

Vermunt, J. D., \& Vermetten, Y. J. (2004). Patterns in student learning: Relationships between learning strategies, conceptions of learning, and learning orientations. Educational Psychology Review, 16, 359-384.

Watkins, D. (1983). Assessing tertiary study processes. Human Learning, 2, 29-37.

Watkins, D., \& Akande, A. (1994). Approaches to learning of Nigerian secondary school children: Emic and etic perspectives. International Journal of Psychology, 29, 165-182.

Wendorf, C. A. (2004). Manuals for univariate and multivariate statistics. http://www.uwsp.edu/psych/ cw/statmanual/. Accessed 10 March 2011.

Wierstra, R. F. A., Kanselaar, G., Van der Linden, J. L., Lodewijks, H. G. L. C., \& Vermunt, J. D. (2003). The impact of the university context on European students' learning approaches and learning environment preferences. Higher Education, 45, 503-523.

Yang, B., Zheng, W., \& Li, M. (2006). Confucian view of learning and implications for developing human resources. Advances in Developing Human Resources, 8, 346-354. 